\title{
Induction of Neutralizing Antibodies against Mutalysin-II from Lachesis muta muta Snake Venom Elicited by a Conformational B-cell Epitope Predicted by Blue Star Sting Data Base
}

Ricardo Andrez Machado-de-Ávila1, Mariana Velloso², Daysiane Oliveira², Stephanie Stransky², Ana Flor-Sá2 ${ }^{2}$, Francisco S. Schneider ${ }^{2}$, Goran $^{2}$ Neshich ${ }^{3}$ and Carlos Chávez-Olórtegui ${ }^{*}$

${ }^{1}$ Unidade Acadêmica de Ciências da Saúde, Universidade do Extremo Sul Catarinense, Criciúma-SC, Brazil

${ }^{2}$ Departamento de Bioquímica-Imunologia, Instituto de Ciências Biológicas, Universidade Federal de Minas Gerais, Belo Horizonte-MG, Brazil

${ }^{3}$ Computational Biology Research Group, Embrapa/Agricultural Informatics, Campinas-SP, Brazil.

\begin{abstract}
Mutalysin-II, from Lachesis muta muta snake venom, is an endopeptidase with hemorrhagic activity. To identify a conformational epitope we used Blue Star Sting, the latest version of the web based Sting Millenium Suite, as alternative computational analysis tool to select and design peptides. Pre-selected cut-off values of the accessibility and hydrophilicity parameters were used to select amino acid residues as potential conformational epitopes. A peptide (P117-Y116-C115-Q194-C195-L197-N198-K199-P200-Y5-L48) was manually drawn on Swiss-PDB-Viewer package and synthesized by Fmoc-synthesis. Immunization of rabbits with this peptide induced antibodies that recognized Mutalysin-II and protected against the hemorrhagic factors present in Lachesis venom. The Sting Millennium Suite was able to predict conformational epitopes in this class of proteins. Three amino acids (K199, Y5 and L48) were identified as essential in the interaction between the peptide and the neutralizing antibodies.
\end{abstract}

Keywords: Lachesis muta muta venom; Antivenom; Sting millennium; Synthetic peptides; Epitopes; Conformational epitope prediction

\section{Introduction}

Snakebites are considered a neglected tropical condition in the World and an important public health problem in Brazil [1]. The pit viper envenomation is generally characterized by severe hemorrhage, blood incoagulability and renal insufficiency. In Bothrops sp. and Lachesis sp. Snake Venoms Metalloproteinases (SVMPs) are the most important contributors to local and systemic hemorrhage observed in human snakebite victims [2]. The venom of the pit viper L. muta muta contains a proteinase, called mutalysin-II (Mut-II) a P-I snake venom metalloproteinase (P-I SVMP) and belongs to a major class of metalloproteinases known as the metzincins [3]. Mut-II is a $22.5 \mathrm{kDa}$ single chained protein with broad substrate specificity and traces of hemorrhagic effects [3,4]. Like other SVMPs, mutalysins proteolytically degrade fibrinogen and other extracellular matrix components such as laminin, fibronectin, and type IV collagen or gelatin [4].

Due to the medical importance of the envenomation caused by the L. muta muta and the role played by P-I SVMPs in these accidents, polyclonal and monoclonal antibodies against these zinc-endopeptidases may be considered as highly useful tools to investigate the structural determinants of toxicity and antigenicity/ immunogenicity of these molecules. Furthermore, these antibodies could have great potential for the preparation of more efficacious antivenoms for passive immunotherapy or even for vaccination. Effectively, the monoclonal antibody LmmAbB2D4 [5] and rabbit polyclonal antibodies [6] against Mut-II efficiently neutralize the hemorrhagic effects of whole L. muta muta venom and certain Bothrops venoms. Prediction and mapping of neutralizing epitopes on these toxic proteins are vital steps to create epitope-based antivenoms design (i.e. antivenoms produced using synthetic peptides corresponding to identified epitopes as immunogens). We have showed that synthetic peptides corresponding to linear and conformational epitopes previously mapped using laboratory methods, are capable of inducing neutralizing antibodies against $L$. muta muta crude venom [6,7].
Although laboratory techniques, such as Phage display [8] and Spot method [9], are effective in identifying epitopes, they are expensive and time consuming. Therefore, computational analysis can provide a rapid method to identify functional epitopes using data routinely collected from toxins. STING Millennium Suite (SMS) [10] is web-based, publicly available software developed to aid researches in their quest for translating information about the structures of macromolecules into knowledge. Using SMS it is possible to analyze the sequence/structure relationship, quality of the structure, nature and volume of intra and inter chain atomic contact and the relative conservation of amino acids at the specific sequence position based on multiple sequence alignment to mention only a few [11]. In the present investigation, we used STING Millennium Suite (SMS) as an alternative computational analysis tool to design and select a peptide with characteristics of conformational epitopes on Mut-II.

\section{Materials and Methods}

\section{Animals and venoms}

Eight-to-nine-week-old female New Zealand white rabbits (2.0-2.5 $\mathrm{kg}$ ) were maintained at the Centro de Bioterismo, ICB-UFMG (Belo Horizonte, MG, Brazil), and received water and food under controlled environmental conditions. Treatment and handling of all animals used in the experiments followed the requirements of the Ethics Committee

*Corresponding author: Dr. Carlos Chávez-Olórtegui, Departamento de Bioquímica e Imunologia, Instituto de Ciências Biológicas, Universidade Federal de Minas Gerais, Avenida Antônio Carlos, 6627, Belo Horizonte, Brazil, Tel: + 55 313409 2625; E-mail: olortegi@icb.ufmg.br

Received October 21, 2014; Accepted December 08, 2014; Published Decembe 10,2014

Citation: Machado-de-Ávila RA, Velloso M, Oliveira D, Stransky S, Flor-Sá A, et al (2014) Induction of Neutralizing Antibodies against Mutalysin-II from Lachesis muta muta Snake Venom Elicited by a Conformational B-cell Epitope Predicted by Blue Star Sting Data Base. Immunome Res 10: 083. doi: 10.4172/17457580.1000083

Copyright: (c) 2014 Machado-de-Ávila RA, et al. This is an open-access article distributed under the terms of the Creative Commons Attribution License, which permits unrestricted use, distribution, and reproduction in any medium, provided the original author and source are credited. 
Citation: Machado-de-Ávila RA, Velloso M, Oliveira D, Stransky S, Flor-Sá A, et al. (2014) Induction of Neutralizing Antibodies against Mutalysin-II from Lachesis muta muta Snake Venom Elicited by a Conformational B-cell Epitope Predicted by Blue Star Sting Data Base. Immunome Res 10: 083. doi: 10.4172/17457580.1000083

Page 2 of 6

of Animal Experimentation (CETEA) of UFMG. L. muta muta venom was obtained by milking specimens captured near Manaus, Amazonas, Brazil and raised at the serpentarium of Fundação Ezequiel Dias (FUNED), Belo Horizonte, Brazil. Mut-II was isolated as previously described by [12].

\section{Molecular modeling of 3D structure of the Mut-II}

Mut-II 3D structure model was constructed based on its homology to atrolysin C (a hydrolase; EC 3.4.24.42) bound to batimastat which is a potent metalloproteinase inhibitor (pdb code: $1 \mathrm{dth} . \mathrm{pdb}$ ) utilizing the Swiss-Model as described earlier [13]. The validation was performed by Anolea tool [14] and the visualization of the model by the DeepView/ Swiss-PDB-Viewer software [15]. The predicted epitope was located in the three-dimensional model of Mut-II and visualized using SwissPDB-Viewer package [15].

\section{Prediction of the epitopes by selecting amino acid residues with specific physical-chemical and structural attributes available in Blue Star Sting database}

Due to the rich repository of protein characteristics offered by BlueStar STING (BSS) platform [16-19], which is the latest version of SMS, has already been used to predict enzyme class [20], proteinligand analysis $[21,22]$, protein mutant analysis [23,24], protein-protein interaction pattern analysis [25] and others [26,27]. In this work, BSS platform was used as a tool to predict a conformational epitope of Mut-II based on its physicochemical properties. For this, we used Java Protein Dossier (JPD) module of BSS [28] as a tool to select amino acids, which could form possible epitopes in the 3D model of the Mut-II. In the JPD, there is a SELECT feature that allows the user to filter conditions that may be used to select amino acid residues which satisfy all indicated numerical and/or descriptive ranges marked in the interactive SELECT window. In this case, our intention was to select those amino acid residues, which satisfy a very simple set of rules: being hidrophilic and possessing the area of accessibility larger than 100 square angstroms. This cascade of two filtering conditions is easily marked in JPD select feature by selecting first: "Relevant Sites" and marking Residue Location (Surface) and then, "Surface Accessibility" and marking Surface Accessibility (Surface Accessibility in Isolation $>100$ ). For hydrophilicity, one shall mark the select feature "Others" and then "Residue Property", marking "Hydrophilic" residues. By pressing OK, those two filters would be applied and only amino acid residues that satisfy both conditions would remain displayed in the JPD window. This procedure was actually the initial step for selecting residues for the final composition of the peptide. Twenty-five residues were selected.

In the last step of the epitope prediction, we proposed a peptide by combining some of these residues with its spatial neighbours. For this, using the Swiss PDB Viewer we visualized in the Mut-II 3D structure the 25 residues selected by the JDP-BSS. We saw that the Y116, Y117, Q194, L197 and K199 residues were spatially near each other (radius smaller than 10 Angstrons). Therefore, to bond these residues to each other and obtain a peptide sequence, we used their spatial neighbours to link one residue to another. The residues used as spatial neighbours were selected for being in the shortest distance from the two residues selected by the JPD-BSS. Thus, in-between Y116 and Q194 residues, we selected the C115 residue for being the spatial neighbour of these two residues. In like manner, in-between Q194 and L197 residues we selected the C195 residue, and in-between L197 and K199 residues we selected the N198 residue. It was not necessary to add a residue in-between P117 and Y116. Lastly we added the P200, Y5 and L48 residues to the end so that the surface formed on the peptide could homogeneous. Therefore in the end, we obtained a peptide composed by discontinuous regions of the Mut-ll: P117-Y116-C115-Q194-C195L197-N198-K199-P200-Y5-L48.

\section{Synthesis, purification and mass spectrometry of soluble peptide}

The peptide PYCQCLNKPYL was synthesized in a ResPep SL/ AutoSpot SL (Intavis, Germany) synthesizer by Fmoc chemistry Technique [29] as adapted by [7]. The peptide was released from the resin by trifluoracetic acid treatment in the presence of the appropriate scavengers. The synthetic peptide $(40 \mathrm{mM})$ was diluted in Milli-Q water $(5 \mathrm{ml})$ and purified by high performance liquid chromatography (HPLC) on a C18 reverse phase column (flow rate $1.0 \mathrm{ml} / \mathrm{min}$; Vydac). The peaks were submitted to MALDI-TOF-TOF analysis.

\section{Immunogen preparation by peptide incorporation in liposomes}

The soluble synthetic peptide was encapsulated in liposomes using the dehydration-rehydration method [30]. A parallel preparation of empty lipossome (PBS-loaded) vesicles was also performed. The fraction of peptide entrapped in the liposomes was determined indirectly by centrifugation $\left(43,000 \times \mathrm{g} ; 30 \mathrm{~min} ; 4^{\circ} \mathrm{C}\right)$ and peptide titration in the supernatant.

\section{Rabbit's immunization}

New Zealand white rabbits were used for the production of antipeptide antibodies. After collection of pre-immune sera, three rabbits received an initial subcutaneous injection of $100 \mu \mathrm{g}$ of synthetic peptide entrapped in liposomes containing aluminum hydroxide (day 1). Nine similar booster injections were made with intervals of 14 days. The animals were bled 1 week after the last injection. As control, two rabbits were also immunized using empty liposomes, prepared as described previously.

\section{Neutralization assays}

Hemorrhagic activity was assayed as described in the Kondo method [31] and adapted by [12]. Aliquots of L. muta muta venom [amount equivalent to 1 minimum hemorrhagic dose (MHD) $/ \mathrm{kg}$ ] in $100 \mu \mathrm{l}$ physiological saline, or saline alone, were injected 15 days after the last immunization, into the dorsal shaved skin of the immunized and control rabbits. Twenty-four hours later, the rabbits were euthanized and the back skin was totally removed in order to photograph and measure the hemorrhagic lesions. The MHD used throughout this study was 20 $\mu \mathrm{g}$, and it was defined as the dose, which causes a hemorrhagic lesion of $10 \mathrm{~mm}$ in diameter.

\section{Enzyme linked immunosorbent assay}

Maxisorp plates (Nunc) were coated overnight at $4^{\circ} \mathrm{C}$ with a 10 $\mu \mathrm{g} / \mathrm{mL}$ solution with three different antigens separately (i.e. designed peptide, mut-II or L. muta muta whole venom) in a Coating buffer, $\mathrm{pH}$ 9.6, and blocked with PBS-Tween $0.1 \%$ containing powdered milk $(30 \mathrm{~g} / \mathrm{L})$. Antibody binding was detected by horseradish peroxidase conjugated goat anti-rabbit whole-IgG (Sigma Aldrich 1:10,000), followed by addition of Sigma Fast OPD tablet (Sigma). Absorbance values were determined at $492 \mathrm{~nm}$ with a Bio-Rad 680 microplate reader.

\section{Western blotting}

For western blotting, $20 \mu \mathrm{g}$ of either L. muta muta crude venom or mut-II were subjected to SDS-PAGE (12\%) in non-reducing conditions. 
Citation: Machado-de-Ávila RA, Velloso M, Oliveira D, Stransky S, Flor-Sá A, et al. (2014) Induction of Neutralizing Antibodies against Mutalysin-II from Lachesis muta muta Snake Venom Elicited by a Conformational B-cell Epitope Predicted by Blue Star Sting Data Base. Immunome Res 10: 083. doi: 10.4172/17457580.1000083

The proteins were transferred onto nitrocellulose membranes and blocked with PBS-Tween $0.3 \%$. The membranes were incubated with either anti-peptide, anti-mut-II or non-immune sera separately (dilution 1:25) for one hour at room temperature. Immunoreactive proteins were detected using anti-rabbit IgG conjugated with peroxidase $(1: 10,000)$ from Sigma. After washing three times for 5 minutes with PBS-Tween $0.05 \%$, blots were developed using $\mathrm{DAB} /$ chloronaphthol, according to the manufacturer's instructions.

\section{Immunoassays with cellulose-bound peptides}

Immunoassay with cellulose-bound peptides was used to evaluate the recognition of epitope-peptide by rabbit anti-peptide serum. Sets of 12 mer-peptides were prepared on cellulose membranes by Spot synthesis [32]. Identification of essential amino acids for binding antibody-peptide was also performed in an ALA-Scan assay. In this experiment a membrane possessing a set of peptides in which each amino acid in the original sequence was replaced by an alanine at a time. The membranes were obtained from Intavis (Koln, Germany) and the F-moc amino acids from Novabiochem. The immunoassay was performed as described in [33]. The anti-peptide rabbit sera were diluted 1:1000 and alkaline-phosphatase conjugated anti-rabbit antibody (Sigma) was diluted 1:3000.

\section{Results}

Molecular modeller and Identification of conformational epitopes

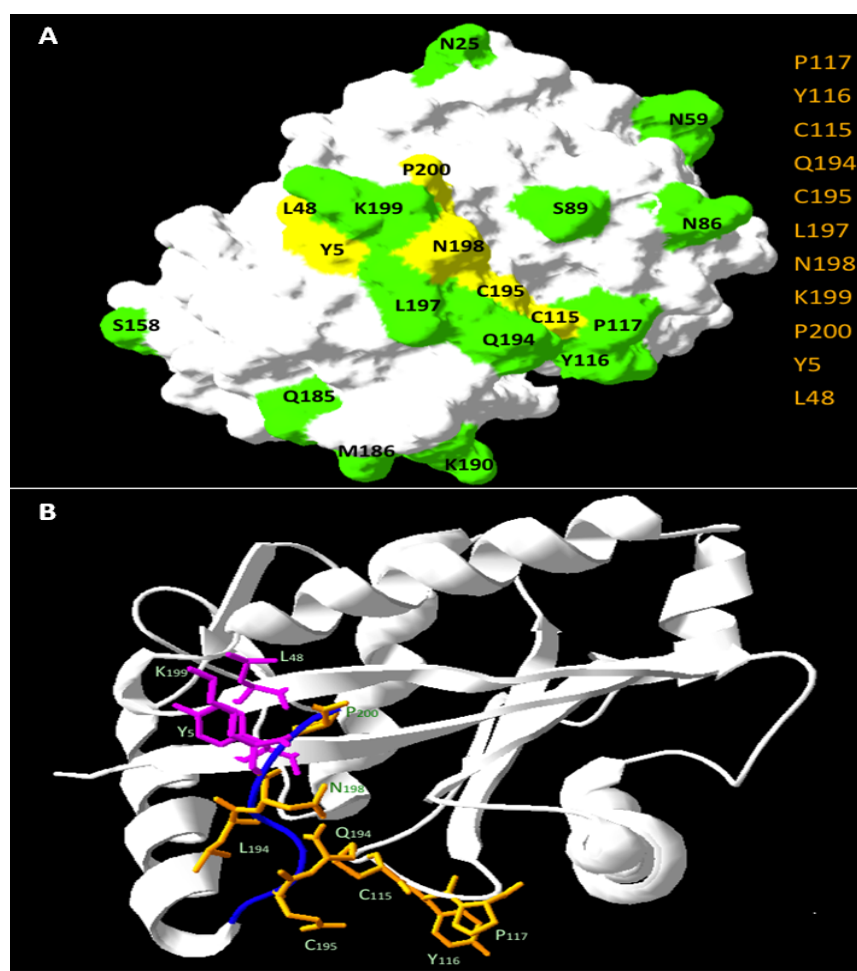

Figure 1: Visualization of the residues selected by STING as epitopes in the Mut-II and a peptide proposed in a 3D structure. In (A): visualization of amino acid residues on the molecular surface of the Mut-II. The amino acid residues selected by STING are in green and the neighbor amino acid residues used to propose the peptide are in yellow. (B): Location of the peptide in the predicted 3D structure of Mut-II. In blue, the C-terminal region; in orange, the amino acids that compose the peptide; and in magenta, the essential amino acids identified by AlaScan.
We used the website BSS platform to predict/select those amino acid residues that could constitute a potential conformational epitope. The BSS itself is not a program for predicting epitopes; it is a web based software for interactive analysis of the sequence/structure/function of proteins and their complexes with DNA and ligands, allowing the user to interactively analyze molecular structures, cross-referencing visualized information with correlated attributers stored in the BSS database [11]. BSS has a module, (the JPD) [28] that communicate a large set of the physicochemical properties of proteins at a residueby-residue level through a unique graphic interface. JPD currently connects to a total of 1540-numerical/textual descriptors for any given protein structure deposited in the PDB in a residue by residue manner $\left(\left(8.89 \times 10^{10}\right.\right.$ records -105000 structures with 2.2 chains in average, with 250 amino acids in average per chain) [10]. We adapted the JPD to select the potential amino acid residues with epitopic function. For this, we used the JPD to select amino acid residues that are both hydrophilic and also have high accessibility in Mut-II. Twenty-five residues were selected by the combination of these parameters, they are: K19, N21, N25, N36, N59, Q60, N64, N70, K74, N86, S89, N104, Y116, P129, K149, N153, S158, P172, Q185, M186, K190, K192, Q194, L197, K199 and can be visualized in the 3D structure of Mut-II (Figure $1 \mathrm{~A}$ and Table 1). The conformational nature of the epitope residue assemblage is evident since the selected residues are not found in a linear sequence in the primary structure. The residues were grouped into two clusters, according to the spatial distance in the 3D structure. The group containing the highest number of selected residues had a peptide designed. The $3 \mathrm{D}$ peptide structure was manually designed in SPDBV tool combining the selected amino acid residues with their spatial neighbours to obtain a peptide with physical-chemical characteristic similar to that of the potential epitopic region of the Mut-II. Thus, the cluster possessing the residues: Y116, P117, Q194,

\begin{tabular}{|c|c|c|}
\hline Amino Acid & Position & Accessibility $\left(\AA^{2}\right)$ \\
\hline $\mathrm{K}$ & 19 & 109.38 \\
\hline $\mathrm{N}$ & 21 & 142.06 \\
\hline $\mathrm{N}$ & 25 & 104.80 \\
\hline $\mathrm{N}$ & 36 & 103.04 \\
\hline $\mathrm{N}$ & 59 & 127.00 \\
\hline$Q$ & 60 & 112.06 \\
\hline $\mathrm{N}$ & 64 & 103.86 \\
\hline $\mathrm{N}$ & 70 & 102.32 \\
\hline $\mathrm{K}$ & 74 & 120.55 \\
\hline $\mathrm{N}$ & 86 & 133.90 \\
\hline$S$ & 89 & 101.50 \\
\hline $\mathrm{N}$ & 104 & 151.70 \\
\hline $\mathrm{Y}$ & 116 & 101.80 \\
\hline$P$ & 117 & 100.90 \\
\hline $\mathrm{K}$ & 149 & 129.29 \\
\hline $\mathrm{N}$ & 153 & 110.05 \\
\hline$S$ & 158 & 113.30 \\
\hline $\mathrm{P}$ & 172 & 129.92 \\
\hline Q & 185 & 115.42 \\
\hline$M$ & 186 & 138.18 \\
\hline $\mathrm{K}$ & 190 & 163.35 \\
\hline $\mathrm{K}$ & 192 & 100.50 \\
\hline Q & 194 & 166.60 \\
\hline$L$ & 197 & 101.60 \\
\hline $\mathrm{K}$ & 199 & 170.63 \\
\hline
\end{tabular}

Table 1: Accessibility Surface of the Selected Residues. 
Citation: Machado-de-Ávila RA, Velloso M, Oliveira D, Stransky S, Flor-Sá A, et al. (2014) Induction of Neutralizing Antibodies against Mutalysin-II from Lachesis muta muta Snake Venom Elicited by a Conformational B-cell Epitope Predicted by Blue Star Sting Data Base. Immunome Res 10: 083. doi: 10.4172/17457580.1000083

A

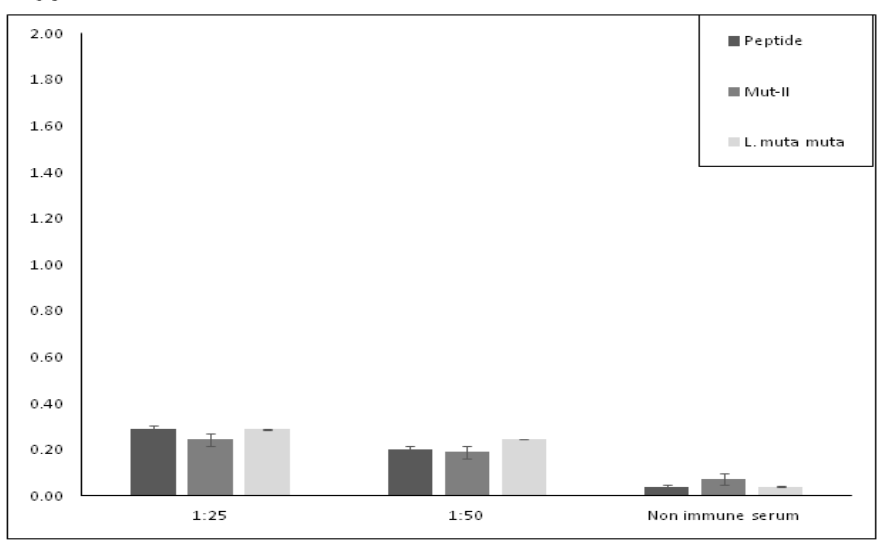

B

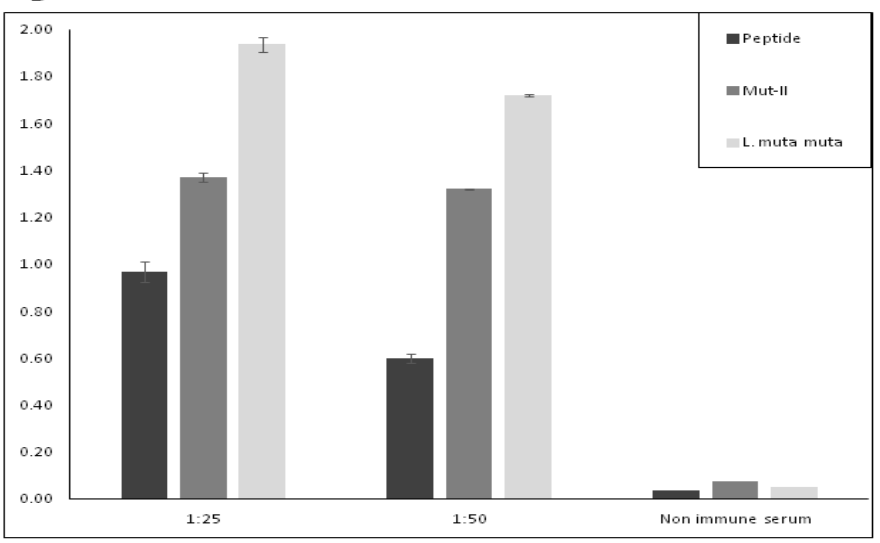

Figure 2: Immunoreactivity of anti-peptide and anti-mut-II against the designed peptide, mutalysin-II and $L$. muta muta venom by ELISA. (A) ELISA showing the reaction of anti-peptide antibodies against peptide, mut-II or L. muta muta whole venom. (B) Anti-mut-II was also tested against the same antigens, showing a stronger but similar pattern of bands recognition compared to anti-peptide serum. In both cases microtiter plates were coated with $10 \mu \mathrm{g} / \mathrm{mL}$ solution of each antigen. The absorbance of the samples was determined at $492 \mathrm{~nm}$

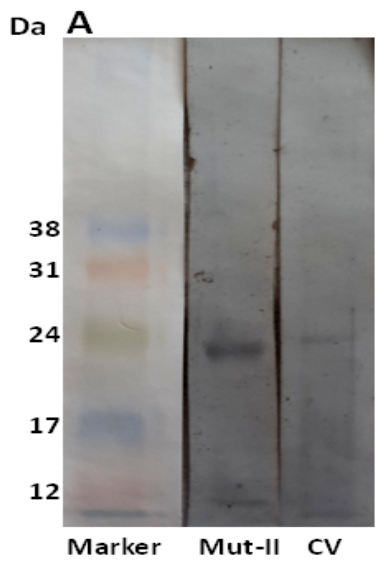

B

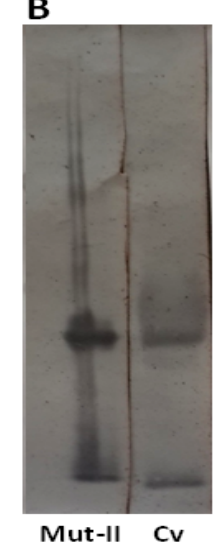

C

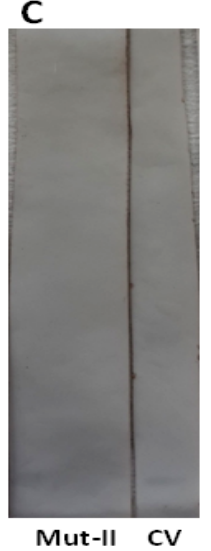

Figure 3: Reactivity of anti-peptide and anti-mut-II sera with mutalysin-II or Lachesis muta muta whole venom analyzed by western blotting. 20 $\mu \mathrm{g}$ of Lachesis muta muta crude venom (CV) and mutalysin-II (Mut-II) were transferred to a nitrocellulose membrane and incubated with rabbit polyclonal anti-peptide (A), anti-mut-II (B) or non-immune (C) sera (all sera were diluted 1:25). Anti-peptide and mut-II recognized bands around $23 \mathrm{kD}$.

L197, K199 (Green at Figure 1A), along with its spatial neighbours, Y5, L48, C115, C195, N198, P200 (Figure 1A), were combined, to obtain the peptide P117-Y116-C115-Q194-C195-L197-N198-K199P200-Y5-L48 (Figure 1B).

\section{Neutralizing ability of anti-peptide antibodies}

In order to confirm it as a conformational epitope, the peptide sequence PYCQCLNKPYL was synthesized and its immunogenicity tested. The peptide was synthesized using Fmoc Chemistry Technique $[7,29]$. The N-terminal portion was acetylated and the C-terminal portion was amidated. Subsequently, it was purified by HPLC in C18 columns and the major peak was validated by mass spectrometry, having an expected monoisotopic mass of $1382.67 \mathrm{Da}$ (data not shown).

After, the peptide was incorporated into liposomes using the dehydration-rehydration method [30]. Then, three New Zealand white rabbits were immunized with liposome containing the peptide. As a control, two rabbits were also immunized with empty liposomes, containing no synthetic peptides. After the first immunization, eight boosters were performed as described before. Seven days after the last immunization the rabbits were bled and their sera were obtained by centrifugation at $3000 \mathrm{rpm}$ for subsequent analysis in ELISA and Western Blotting.

Antibodies raised against the designed peptide were able to recognize both purified mut-II and L. muta muta crude venom in ELISA (Figure 2A) and in Western Blotting (Figure 3A) in a similar manner compared to anti-mutalysin-II serum (Figure $2 \mathrm{~B}$ and Figure 3B). Fifteen days after the last immunization, we conducted a hemorrhagic assay to verify whether this peptide would also be capable of inducing the production of neutralizing antibodies against the hemorrhagic toxins in L. muta muta venom. Thus, $20 \mu \mathrm{g} / \mathrm{Kg}$ of L. muta muta venom were injected intradermally into immunized rabbits and after 24 hours the rabbits were euthanized in a $\mathrm{CO}_{2}$ chamber and their skins were removed in order to analyze the hemorrhagic lesions caused by the venom. Figure 4 shows the visceral side of the skins removed from the dorsum of the rabbits. The two rabbit controls, which received only the liposome without peptides during their immunizations, showed the greater hemorrhagic injury. In contrast, the three rabbits immunized with the peptide showed no signs of bleeding, thus indicating that immunizations were efficient for the production of neutralizing antibodies against bleeding factors in the venom of L. muta muta.

To verify which amino acids residues in the peptide were important in the interaction with rabbit anti-PYCQCLNKPYL polyclonal antibodies, a series of alanine analogs of the peptide was prepared by Spot synthesis and assayed for reactivity against anti-PYCQCLNKPYL antibodies. In each spotted peptide, an amino acid at a time was substituted by alanine. The results (Figure 5) indicate that in the C-terminal part of the peptide some residues could not be changed into alanine without decreasing their antibody binding capacity: this is the case for residues Lys8, Tyr10 and Leu11. These residues are, thus, key contributors in this antigenic region of the predicted conformational epitope of mutalisin-II. Residues in the $\mathrm{N}$-terminal part of the peptide 
Citation: Machado-de-Ávila RA, Velloso M, Oliveira D, Stransky S, Flor-Sá A, et al. (2014) Induction of Neutralizing Antibodies against Mutalysin-II from Lachesis muta muta Snake Venom Elicited by a Conformational B-cell Epitope Predicted by Blue Star Sting Data Base. Immunome Res 10: 083. doi: 10.4172/17457580.1000083

Page 5 of 6

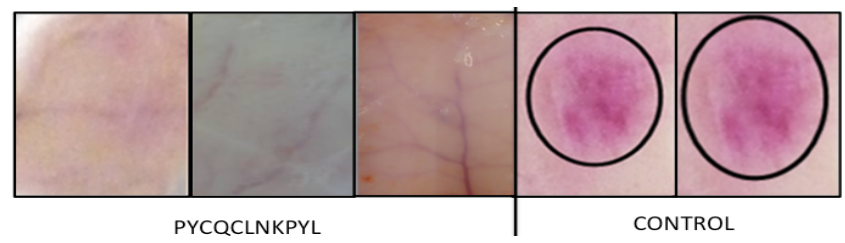

Figure 4: The in vivo neutralization assays of the hemorrhagic activity of $L$. muta muta venom. The immunized and control rabbits were challenged with $L$. muta muta venom 15 days after the last immunization by intradermal injection of an amount equivalent to $1 \mathrm{MND} / \mathrm{kg}$.

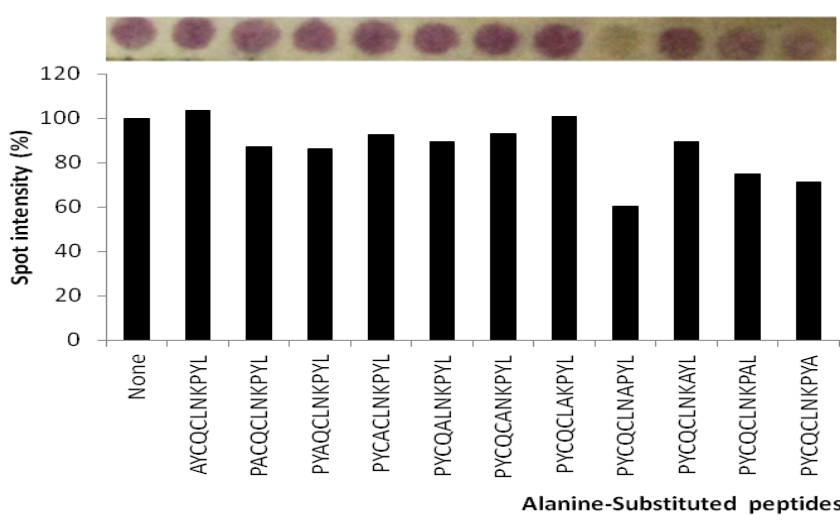

Figure 5: Reactivity of ALA-Scan peptides. Anti-peptide rabbit sera reactivity with cellulose-bound peptides was detected with an alkalinephosphatase coupled anti-rabbit antibody. Spot intensities were measured with the Scion Image software. Reactivity below 75000 was considered negative.

play minor roles in antibody recognition.

\section{Discussion}

The peptide sequence PYCQCLNKPYL was designed in silico as a conformational epitope previously using BSS analysis, which selected only hydrophobic and solvent accessible amino acid residues above determined threshold. This peptide entrapped in liposomes was used to determine its immunogenicity in rabbits. Liposomes are biodegradable particles considered an excellent form to deliver biologically active substances [35]. The gradual release is essential to increase the lifetime of the peptide during its presentation to the immune system, which can improve the production of specific antibodies [36]. Anti-peptide sera produced in liposomes recognized mut-II and L. muta muta venom in ELISA and Western Blotting.

To measure the in vivo neutralization capacity of anti-peptide antibodies against the hemorrhagic activity of $L$. muta muta venom, the immunized rabbits were injected with $L$. muta muta crude venom $[12,30]$. Pre-existing rabbit anti-peptide antibodies neutralize efficiently the hemorrhagic activity of the crude L. muta muta venom [6]. Thus, it is reasonable to assume that anti-peptide serum binds to the SVMPs of the crude venom. Tanjoni et al. 2003, reported the binding of a monoclonal antibody to the disintegrin-like domain of jararhagin, a PIII-class metalloproteinase, neutralizing completely the hemorrhagic activity of the toxin. This domain is located at the C-terminal portion of the toxin. They supposed that the mechanism of this neutralization is due the proximity of this domain to the catalytic site of the protein, which probably prevented the interaction between enzyme and substrate, thus causing neutralization [37]. Our designed peptide possesses amino acid residues located near the C-terminal region of Mut-II, as shown in Figure 1B. Despite the differences between Mut-II and jararhagin, antibodies anti-peptide of $L$. muta venom might present allosteric inhibitor mechanism. The binding of the antibody in a region spatially near the C-terminal portion of the Mut-II could cause a steric shielding of the catalytic site, blocking its binding to the substrate and thereby inhibiting the hemorrhagic effect of the toxin. The absence of K199, L48 and Y5 in analogous peptides decreases their reactivity with antibodies (identified by alanine-scanning), therefore suggesting that these amino acids are essential for the interaction with antibodies.

In this way, we suppose that the in silico designed peptide represents a discontinuous or conformational B-cell epitope capable to induce neutralizing antibodies against the hemorrhagic factor of the L. muta muta venom. Parameters such as the hydrophilicity, static accessibility and mobility of short segments of polypeptide chains have been correlated with the location of continuous epitopes in proteins [38]. B cell epitopes contain both continuous ( 10\%) and discontinuous ( 90\%) epitopes, therefore the majority of B-cell epitopes are discontinuous. Currently, only a few methods and prediction tools for discontinuous B-cell epitopes are available, and their performance is generally very poor, because they lack experimental verification [39]. Our results suggest that the accessibility and hydrophilicity are also imortant parameters and may be used as facilitators to predict a conformational epitope in toxic proteins. Different bioinformatics programs use specific groups of parameters, varying from one another, including in hydrophobicity, antigenicity, flexibility, accessibility, amino acids considered as special in the interactions with antibodies, segmental mobility, among others, resulting in the prediction of different epitopes, depending on the accuracy of these programs (nowadays, the programs for the prediction of epitopes have a range of accuracy varying from 35-75\%) [40]. In conclusion, our results show the generation and characterization of a neutralizing conformational epitope against Mut-II from L. muta muta venom and that the accessibility and hydrophilicity are important parameters to predict conformational epitopes in this class of proteins.

\section{Acknowledgments}

This research was supported by Coordenação de Aperfeiçoamento de Pessoal de Nível Superior, Brazil - CAPES (Toxinologia № 23038000825/2011-63) Fundação de Amparo a Pesquisa do Estado de Minas Gerais, Brazil (FAPEMIG) and by funds of the INCTTOX Program of Conselho Nacional de Desenvolvimento Científico e Tecnológico, Brazil (CNPq). We would like to thank the Núcleo de Estudo de Estrutura e Função de Biomoléculas [Departamento de Bioquímica e Imunologia, Instituto de Ciências Biológicas, Universidade Federal de Minas Gerais (UFMG), Belo Horizonte, Minas Gerais, Brasil] for technical support for mass spectrometry.

\section{References}

1. SINAN - Ministério da Saúde (2014) "Acidentes por animais peçonhentos" Secretaria Nacional de Ações Básicas de Saúde do Brasil.

2. Jorge MT, Sano-Martins IS, Tomy SC, Castro SC, Ferrari RA, et al. (1997) Snake bite by the bushmaster (Lachesis muta) in Brazil: case report and review of the literature. Toxicon 35: 545-554.

3. Sanchez EF, Souza CT, Bello CA, Richardson M, Oliveira EB, et al. (2003) Resolution of isoforms of mutalysin II, the metalloproteinase from bushmaster snake venom. Toxicon 41: 1021-1031.

4. Sanchez EF, Cordeiro MN, De Oliveira EB, Juliano L, Prado ES, et al. (1995) Proteolytic specificity of two hemorrhagic factors, LHF-I and LHF-II, isolated from the venom of the bushmaster snake (Lachesis muta muta). Toxicon 33:1061-1069

5. Estevão-Costa MI, Martins MS, Sanchez EF, Diniz CR, Chavez-Olortegui C (2000) Neutralization of the hemorrhagic activity of Bothrops and Lachesis snake venoms by a monoclonal antibody against mutalysin-II. Toxicon 38: 139144. 
Citation: Machado-de-Ávila RA, Velloso M, Oliveira D, Stransky S, Flor-Sá A, et al. (2014) Induction of Neutralizing Antibodies against Mutalysin-II from Lachesis muta muta Snake Venom Elicited by a Conformational B-cell Epitope Predicted by Blue Star Sting Data Base. Immunome Res 10: 083. doi: 10.4172/17457580.1000083

6. Ferreira RN, Machado de Avila RA, Sanchez EF, Maria WS, Molina F, et al. (2006) Antibodies against synthetic epitopes inhibit the enzymatic activity of mutalysin II, a metalloproteinase from bushmaster snake venom. Toxicon, 48 : 1098-1103

7. Machado de Avila RA, Stransky S, Velloso M, Castanheira P, Schneider FS, et al. (2011) Mimotopes of mutalysin-II from Lachesis muta snake venom induce hemorrhage inhibitory antibodies upon vaccination of rabbits. Peptides 32 1640-1646.

8. Hell RC, Amim P, de Andrade HM, Machado de Avila RA, Felicori L, et al. (2009) Immunodiagnosis of human neurocysticercosis using a synthetic peptide selected by phage-display. Clin Immunol 131: 129-138.

9. Frank R (1992) Spot-synthesis: an easy technique for the positionally addressable, parallel chemical synthesis on a membrane support. Tetrahedron 48: 9217-9232.

10. Neshich G, Togawa RC, Mancini AL, Kuser PR, Yamagishi ME, et al. (2003) Sting Millennium: A web-based suite of programs for comprehensive and simultaneous analysis of protein structure and sequence. Nucleic Acids Res, 31: 3386-3392.

11. Higa RH, Togawa RC, Montagner AJ, Palandrani JC, Okimoto IK, et al. (2004) STING Millennium Suite: integrated software for extensive analyses of $3 \mathrm{~d}$ structures of proteins and their complexes. BMC Bioinformatics 5:107.

12. Sanchez EF, Diniz CR, Richardson M (1991) The complete amino acid sequence of the haemorrhagic factor LHFII, a metalloproteinase isolated from the venom of the bushmaster snake (Lachesis muta muta). FEBS Lett 282 178-182.

13. Schwede T, Kopp J, Guex N, Peitsch MC. (2003) SWISS-MODEL: An automated protein homology-modeling server. Nucleic Acids Res 31: 3381-3385.

14. Guex N, Peitsch MC (1997) SWISS-MODEL and the Swiss-PdbViewer: An environment for comparative protein modeling. Electrophoresis 18: 2714-2723.

15. Melo F, Feytmans E (1998) Assessing protein structures with a non-local atomic interaction energy. J Mol Biol 277: 1141-1152.

16. Mancini AL, Higa RH, Oliveira A, Dominiquini F, Kuser PR, et al. (2004) STING Contacts: a web-based application for identification and analysis of amino acid contacts within protein structure and across protein interfaces. Bioinformatics 20: $2145-2147$

17. Neshich G, Borro LC, Higa RH, Kuser PR, Yamagishi ME, et al. (2005) The Diamond STING server. Nucleic Acids Res 33: 29-35.

18. Neshich G, Mancini AL, Yamagishi ME, Kuser PR, Fileto R, et al. (2005) STING Report: convenient web-based application for graphic and tabular presentations of protein sequence, structure and function descriptors from the STING database. Nucleic Acids Res 33: 269-274.

19. Neshich G, Mazoni I, Oliveira SR, Yamagishi ME, Kuser-Falcão PR, et al. (2006) The Star STING server: a multiplatform environment for protein structure analysis. Genet Mol Res 5: 717-722.

20. Boro LC, Oliveira SR, Yamagishi ME, Mancini AL, Jardine JG, et al. (2006) Predicting enzyme class from protein structure using Bayesian classification. Genet Mol Res 5: 193-202.

21. de Freitas SM, de Mello LV, da Silva MC, Vriend G, Neshich G, et al. (1997) Analysis of the black-eyed pea trypsin and chymotrypsin inhibitor alphachymotrypsin complex," FEBS Letters 409: 121-127.

22. Fernandez JH, Hayashi MA, Camargo AC, Neshich G (2003) Structural basis of the lisinopril-binding specificity in $\mathrm{N}$ - and $\mathrm{C}$-domains of human somatic ACE. Biochem and Biophys Res Comm 308: 219-226.

23. Marcellino LH, Neshich G, Grossi de Sá MF, Krebbers E, Gander ES (1996) Modified 2S albumins with improved tryptophan content are correctly expressed in transgenic tobacco plants. FEBS Letters 385: 154-158.

24. Simões M, Bahia D, Zerlotini A, Torres K, Artiguenave F, et al. (2007) Single

Citation: Machado-de-Ávila RA, Velloso M, Oliveira D, Stransky S, Flor Sá A, et al. (2014) Induction of Neutralizing Antibodies against Mutalysin-II from Lachesis muta muta Snake Venom Elicited by a Conformational B-cell Epitope Predicted by Blue Star Sting Data Base. Immunome Res 10: 083. doi: 10.4172/17457580.1000083 nucleotide polymorphisms identification in expressed genes of Schistosoma mansoni. Mol Biochem Parasitology 154: 134-140

25. Melo RC, Ribeiro C, Murray CS, Veloso CJ, da Silveira CH, et al. (2007) Finding protein-protein interaction patterns by contact map matching. Genet Mol Res 6: 946-963.

26. Braghini CA, Neshich IA, Neshich G, Soardi FC, de Mello MP (2013) New mutation in the myocilin gene segregates with juvenile-onset open-angle glaucoma in a Brazilian Family. Gene 523: 50-57.

27. Dias-Lopes C, Neshich IA, Neshich G, Ortega JM, Granier C, et al. (2013) Identification of New Sphingomyelinases D in Pathogenic Fungi and Other Pathogenic Organisms. PlosOne 8: e79240.

28. Neshich G, Rocchia W, Mancini AL, Yamagishi ME, Kuser PR, et al (2004) JavaProtein Dossier: a novel web-based data visualization tool for comprehensive analysis of protein structure. Nucleic Acids Res 32: 595-601.

29. Merrifield RB (1963) Solid-phase peptide synthesis. Adv Enzymol Relat Areas Mol Biol 221-296.

30. Gomes MT, Guimarães G, Frézard F, Kalapothakis E, Minozzo JC, et al. (2011) Determination of sphingomyelinase-D activity of Loxosceles venoms in sphingomyelin/cholesterol liposomes containing horseradish peroxidase. Toxicon 57: 574-579.

31. Kondo H, Kondo S, Ikezawa H, Murata R (1960) Studies on the quantitative method for determination of hemorrhagic activity of Habu snake venom. Jpn J Med Sci Biol 13: 43-52

32. Molina F, Laune D, Gougat C, Pau B, Granier C (1996) Improved performances of spot multiple peptide synthesis. Pept Res 9: 151-155.

33. Horta CC, Magalhães B de F, Oliveira-Mendes BB, do Carmo AO, Duarte CG et al. (2014) Molecular, immunological, and biological characterization of Tityus serrulatus venom hyaluronidase: new insights into its role in envenomation. PLoS Negl Trop Dis 8: e2693.

34. Schneider CA, Rasband WS, Eliceiri, KW (2012) "NIH Image to ImageJ: 25 years of image analysis". Nature Methods 9: 671-675.

35. Taneichi M, Ishida H, Kajino K, Ogasawara K, Tanaka Y, et al. (2006) Antigen chemically coupled to the surface of liposomes are cross-presented to CD8+ cells and induce potent antitumor immunity. J Immunol 177: 2324-2330.

36. Taneichi M, Tanaka Y, Kakiuchi T, Uchida T (2010) Liposome-coupled peptides induce long-lived memory CD8 T cells without CD4 T cells. PLoS One 5 : e15091.

37. Tanjoni I, Butera D, Bento L, Della-Casa MS, Marques-Porto R, et al. (2003) Snake venom metalloproteinases: structure/function relationships studies using monoclonal antibodies. Toxicon 42: 801-808.

38. Van Regenmortel MH, Altschuh $\mathrm{D}$, Chatellier J, Christensen L, Rauffer-Bruyère $\mathrm{N}$, et al. (1998) Measurement of antigen-antibody interactions with biosensors. J Mol Recognit 11: 163-167.

39. Pavlovic MD, Jandrlic DR, Mitic NS (2014) Epitope distribution in ordered and disordered protein regions. Part B - Ordered regions and disordered binding sites are targets of T- and B-cell immunity. J Immunol Methods 407: 90-107.

40. Kulkarni-Kale U, Bhosle S, Kolaskar AS (2005) CEP: a conformational epitope prediction server. Nucleic Acids Res 3: 168-171.

Submit your next manuscript and get advantages of OMICS Group submissions

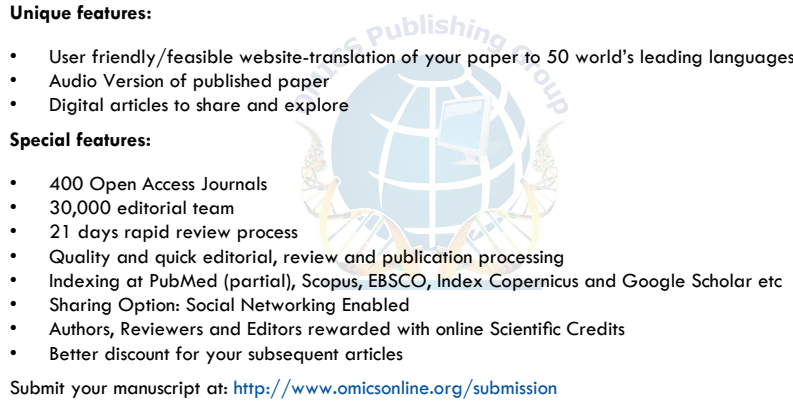

Submit your manuscript at: http://www.omicsonline.org/submission 